\title{
Metabolic rates scale isometrically in larval fishes
}

\author{
Louis A. Giguère ${ }^{1}$, Brenda Côté ${ }^{2}$, J.-F. St-Pierre ${ }^{1}$ \\ ${ }^{1}$ Institut Maurice Lamontagne, Ministère des Pêches et des Océans, C. P. 1000, Mont-Joli, Québec, Canada G5H 3Z4 \\ ${ }^{2}$ Institut National de la Recherche Scientifique, 310 ave. des Ursulines, Rimouski, Québec, Canada G5L 3A1
}

\begin{abstract}
We estimated the rate of oxygen consumption of larval Atlantic mackerel Scomber scombrus at 3 temperatures $\left(13,16,19^{\circ} \mathrm{C}\right)$ while controlling rigorously for methodological biases. Routine metabolic rates $\left(\mu \mathrm{l} \mathrm{O}_{2} \mathrm{~h}^{-1}\right.$ ind. ${ }^{-1}$ ) increase with body weight ( $\mathrm{W}$, in $\mathrm{mg}$ ) and temperature $(\mathrm{T}$, in $\left.{ }^{\circ} \mathrm{C}\right)$ as: $\mathrm{RMR}=2.168 \cdot \mathrm{W}^{1000} \cdot \mathrm{e}^{0.058 \mathrm{~T}}\left(\mathrm{r}^{2}=0.96\right)$. Thus metabolic rates scale isometrically with respect to body weight in larval Atlantic mackerel. This finding is at variance with results obtained for juvenile and adult fishes which follow an allometric relationship $\left(\mathrm{W}^{0.8}\right)$.
\end{abstract}

\section{INTRODUCTION}

It has been suggested that metabolic rates of animals at rest (standard metabolism) or of animals restrained to minimal activity (routine metabolism) increase with body weight (W) at a rate of about $\mathrm{W}^{0.75}$ (Kleiber 1961, Gould 1966, Peters 1983, Schmidt-Nielsen 1984). This empirical 'allometric law' is often used in conjunction with other allometric relationships to study the physiological ecology of terrestrial and aquatic animals. It is also used to estimate food requirements of growing animals using balanced energy budget equations. In fish studies, the most commonly observed value for the metabolic exponent is 0.8 (Winberg 1956, Fry 1957, Schmidt-Nielsen 1984). Exponents near unity have been reported however for larval fish (Holliday et al. 1964, Laurence 1973, 1978. Cetta \& Capuzzo 1982, Houde \& Schekter 1983, Quantz \& Tandler 1984). Unfortunately, estimates of the metabolic exponent published for larval fish range widely (0.65 to 1.69), including values expected if metabolic rates vary in direct proportion to body weight, in which case the relationship is termed isometric (the metabolic exponent is 1), and values expected if metabolic rates do not increase in proportion to body weight. In the latter case the relationship is termed allometric and the metabolic exponent is either greater or less than 1 . Since statistical and methodological biases are common and confounded among studies (see 'Methods'), it is difficult to draw a firm conclusion as to whether the relationship between metabolic rates and body weight is isometric or allometric in larval fish.

Here we establish the relationship between meta- bolic rates and body weight for larvae of mackerel Scomber scombrus, while controlling rigorously for methodological biases. Comparison of our results with those of other studies (correcting for statistical bias) leads us to postulate that metabolic rates scale isometrically in larval fishes.

\section{MATERIALS}

All experiments were carried out during the $3 \mathrm{yr}$ period from 1984 to 1987 . Adult Scomber scombrus were caught in the region of Shippagan, New Brunswick (Canada), using drift nets set down to 10 or $15 \mathrm{~m}$. Eggs extruded from 2 females were put on a sieve and fertilized using milt from 2 males. The eggs were then washed and put in a clean bucket of sea water. Penicillin and streptomycin were added at a concentration of $1 \mathrm{mg} \mathrm{l}^{-1}$ and $5 \mathrm{mg} \mathrm{l}^{-1}$ respectively. Three or 4 buckets were prepared before returning to the laboratory. Eggs were then transferred to 401 circular fibreglass containers (Hughes et al. 1974) while keeping temperature differences within $1 \mathrm{C}^{\circ}$. A small amount of unfiltered sea water was continuously supplied to the containers. Temperature increased gradually from about $14{ }^{\circ} \mathrm{C}$ in early June to $19^{\circ} \mathrm{C}$ in mid-July. It declined again to $17^{\circ} \mathrm{C}$ in August.

The rotifer Brachionus plicatilis was cultured according to Reguera (1984) and Lubzens (1987). Rotifers were introduced into the rearing tanks at an average density of 5 ind. $\mathrm{ml}^{-1}$ for the first $5 \mathrm{~d}$ after larval hatching, except in 1987 when we used natural prey instead. Subsequently, larvae were fed with natural prey col- 
lected with conical plankton nets (mesh size $=80$ or $150 \mu \mathrm{m}$ ) towed from a boat with outboard motors. Nauplii and copepods were presented at concentrations of about 3 and 1 ind. $\mathrm{ml}^{-1}$ respectively. The most abundant copepods by number were: Oithona sp., Temora longicornis and Pseudocalanus minutus. Species of Eurytemora, Acartia, and Calanus were present but rare. Attempts to match larval and prey sizes according to data in Hunter \& Kimbrell (1980) and Côté (unpubl.) were made by increasing the size range of prey offered to the larvae as they grew. Prey length varied between 0.08 and $0.50 \mathrm{~mm}$. Samples of prey were taken in the rearing tanks at least 5 times daily and density was adjusted accordingly.

\section{METHODS}

Statistical methods. The allometric equation, $\mathrm{Y}=$ $a W^{b}$, describing the relationship between metabolic rate (Y) and weight (W) of organisms, is usually adjusted to data by linear regression of a log-transformed $x$-variate on a log-transformed $y$-variate $\{\ln (Y)$ $=\ln (a)+b \ln (W)\}$. Glass (1969) noted that the way in which the error term in the $y$-variate enters the equation is of critical importance. When the error term is additive instead of multiplicative (as is the case following logarithmic transformation), metabolic rate measurements made on smaller individuals will be given greater weight than measurements made on larger individuals. Estimates of $\mathrm{b}$ will therefore be biased. The bias is greater as the range of the $x$-variate increases and as the scatter of the data points is large. If the data spread of the $x$-variate is uneven (Peters 1983) or if the unit of the logarithmic transformation lies outside the range of the $x$-variate, additional bias will arise (Donhoffer 1986).

In metabolic studies, a further source of bias arises from the fact that the $x$-variate is also subject to error. Hence functional rather than predictive regression must be fitted to the data series (Ricker 1973). This distinction is frequently overlooked. Misuse of predictive regressions can lead to erroneous conclusions, as demonstrated by Ricker (1973) and Laws \& Archie (1981) in the case of metabolic rate measurements of adult fish.

We attempted to lessen some of these problems in our study by taking the following precautions: (1) We used a natural logarithm because its base lies within the range of values of the $x$-variate. (2) We excluded larvae weighing more than $4.6 \mathrm{mg}$ dry wt to obtain an even spread of the independent variable. Six data points ranging up to $10.8 \mathrm{mg}$ dry wt were eliminated in this fashion. (3) We used polarographic techniques because their accuracy reduces the error on the $y$ - variate (Table 1). (4) Metabolic and dry weight measurements were made on individual larvae to reduce the error on the $x$-variate. (5) Larvae were not preserved before dry weight measurements were made. Many studies preserve organisms in formaldehyde prior to dry weight determination although dry weight losses due to chemical preservation are size dependent (Hay 1984, Giguère et al. in press); this would increase the error on the $x$-variate. (6) We used functional regressions instead of predictive regressions (Ricker 1973). Finally, (7) we validated the parameter estimates obtained using the linear method by comparing them to estimates obtained using a non-linear iterative technique (Glass 1969, Mittertreiner \& Schnute 1985, Theilacker 1987).

Note that in the following text, the slope of the regression equation (log-transformed data) is referred to as the metabolic exponent and that the coefficient (the anti-log of the $y$-intercept) is referred to as the metabolic coefficient, in reference to their respective roles in the power function expression of the allometric equation $\mathrm{Y}=\mathrm{a} \mathrm{W}^{\mathrm{b}}$.

Respirometry. Precautions were taken to avoid bacterial contamination. Sea water was filtered with a $0.2 \mu \mathrm{m}$ Gelman capsule, and glass chambers were sterilized in an autoclave prior to each experiment (Luer lock type glass syringes, Laughlin et al. 1979). The use of Plexiglas ${ }^{T M}$ was avoided because it is porous. This material which is used frequently to build respirometer chambers allows gas exchange. Since the exchange rate will depend upon wall thickness and upon oxygen concentrations on either side of it, and since these concentrations change over time during rate of oxygen consumption measurements, Plexiglas ${ }^{T M}$ chambers should not be used.

All fish used for metabolic rate determinations had empty guts. Since time to empty the gut takes between 5 and $10 \mathrm{~h}$ in larval Atlantic mackerel depending on temperature and body size (Giguère unpubl.), a minimum starvation period of $11 \mathrm{~h}$ was adopted to ensure that metabolic rates had reached stable values after feeding. Consequently, the night before an experiment, 24 fish were collected and transferred to foodless glass containers kept in a temperature controlled water bath at 13,16 or $19^{\circ} \mathrm{C}\left( \pm 0.1 \mathrm{C}^{\circ}\right)$. Eleven to $18 \mathrm{~h}$ later (depending on temperature, larval body size), larvae were introduced into respirometer chambers after dipping them in filtered seawater to avoid introducing large volumes of water from the holding containers which may have been contaminated by food and fecal materials. One glass bead was also introduced into each 30 or $50 \mathrm{ml}$ chamber (depending on the size of a larva). At the same time 2 or 3 chambers were prepared as controls by adding 1 glass bead and 2 or 3 drops of water from the overnight holding contain- 
ers. Each chamber was topped with filtered sea water and gas bubbles were expelled by inserting the piston to the first volumetric marking. A rubber plug was inserted onto the tip of the needle to prevent gas exchanges and the chamber was put back into the temperature controlled water bath. Overall, this operation took less than 5 min. Light intensity in the water bath was about $5 \mu$ Einsteins $\mathrm{m}^{-2} \mathrm{~s}^{-1}$. Larvae were allowed at least $90 \mathrm{~min}$ to acclimate to these new conditions. To verify whether fish were still under stress following transfer to the respirometer chambers, we compared the rate of oxygen consumption among the first 3 samples at the beginning of an experiment. Assuming that fish did not have sufficient time to acclimate to their new conditions, differences in rate of oxygen consumption would be expected between samples. Based on paired $t$-tests, no significant differences were observed in any of the experiments $\left(p>0.08,0.15\right.$ and 0.34 , at 13,16 and $19^{\circ} \mathrm{C}$ respectively).

Aliquot samples for $\mathrm{O}_{2}$ measurement were obtained as follows. A chamber was removed from the temperature controlled water bath and its contents mixed by rolling the glass bead up and down the barrel 8 to 10 times. The rubber plug was replaced by a $90 \mu$ glass capillary tube. The piston was then used to flush at least $1 \mathrm{ml}$ of seawater through the tube. Oxygen concentration of the sample in the capillary tube was determined immediately using a blood gas analyzer (International Laboratory Model 1302, polarographic oxygen electrode). The electrode was calibrated automatically at 20 min intervals. Aliquots were taken from each chamber at intervals varying from 45 to $180 \mathrm{~min}$. The time interval was such that 4 or 5 aliquots could be obtained before the partial pressure of oxygen in the chamber dropped below $50 \%$ saturation. This depended on the experimental temperature and the size of the larva. Within these constraints, there was no effect of $\mathrm{O}_{2}$ saturation on rate of oxygen consumption for our data (analysis of covariance, $p>0.25$ ).

Rate of oxygen consumption, given as $\mu \mathrm{h}^{-1}$ ind. ${ }^{-1}$ was obtained as follows: First, we corrected the raw data for barometric pressure according to the formula of Laughlin et al. (1979). Second, we corrected chamber volume for seawater displaced by the glass bead, the larva, and the sea water removed with each aliquot sample. Third, we corrected for the temperature of the polarographic electrode $\left(25 \pm 0.1 \mathrm{C}^{\circ}\right.$; see HedleyWhyte et al. 1965) using the calibration method described in Carritt \& Carpenter (1966). Fourth, when control chambers showed a small change in oxygen pressure (a rare event), we applied a proportional correction.

All larvae which were sluggish or dead were eliminated from the analysis. Fresh dry weights were obtained after rinsing larvae with a few $\mathrm{ml}$ of distilled water. Larvae were dried in an oven at $60^{\circ} \mathrm{C}$ until they reached a stable weight (usually 24 to $48 \mathrm{~h}$ ). Weighing was to the nearest $\mu \mathrm{g}$ (Cahn electrobalance Model 27). Larval length ranged from 4 to $20 \mathrm{~mm}$.

\section{RESULTS}

The relationship between routine metabolic rates (RMR) and body weight of larvae of Atlantic mackerel Scomber scombrus (log-transformed data) is shown in Fig. 1 for 3 experimental temperatures tested $(13,16$, $\left.19^{\circ} \mathrm{C}\right)$. All 3 regressions were highly significant $(p<<$ 0.01 ). The equivalent power functions of the relationships between RMR ( $\mu \mathrm{l} \mathrm{h} \mathrm{h}^{-1}$ ind. ${ }^{-1}$ ) and $\mathrm{W}$ are:

$$
\begin{array}{llll}
13^{\circ} \mathrm{C} & \mathrm{RMR}=1.468 \cdot \mathrm{W}^{0.97} & \mathrm{r}^{2}=0.94 & n=36 \\
16^{\circ} \mathrm{C} & \mathrm{RMR}=1.720 \cdot \mathrm{W}^{1.00} & \mathrm{r}^{2}=0.95 & n=53 \\
19^{\circ} \mathrm{C} & \mathrm{RMR}=1.826 \cdot \mathrm{W}^{0.99} & \mathrm{r}^{2}=0.98 & n=21
\end{array}
$$

To include the effect of temperature ( $T$ ) on the metabolic coefficients in a generalized equation relating metabolic rates to body weight of a larva, a multiple regression technique similar to that of Peters (1983) and Ikeda (1985) was adopted. The regression model is: $\ln (R M R)=a+b \cdot \ln (W)+c \cdot T$. The power function equivalent of this relationship is: $Y=a W^{b} \cdot e^{c \cdot T}$. The equation obtained was highly significant (sample size $\left.=110, r^{2}=0.96 ; p<<0.01\right)$. The relationship between RMR, $W$, and $T$ is:

$$
\operatorname{RMR}\left(\mu \mathrm{l} \mathrm{h}^{-1} \text { ind }^{-1}\right)=2.168 \cdot \mathrm{W}^{1.000} \cdot \mathrm{e}^{0.058 \cdot \mathrm{T}}
$$

The $95 \%$ confidence intervals of the metabolic exponents are 0.956 and 1.044 , and hence overlap the isometric value ' 1 '. Using, as suggested by Glass (1969), a non-linear iterative curve fitting technique (Mittertreiner \& Schnute 1985) to derive the parameter estimates yielded very similar results:

$$
\operatorname{RMR}\left(\mu \mathrm{l} \mathrm{h}^{-1} \text { ind }^{-1}\right)=2.658 \mathrm{~W}^{0.984} \mathrm{e}^{0.047 \cdot \mathrm{T}}
$$

The $95 \%$ confidence intervals of the metabolic coefficient are, in the latter case, 0.940 and 1.024. This overlaps the estimate obtained using the linear regression procedure, and again the isometric value ' 1 '. We conclude from this that metabolic rates increase in direct proportion to body weight in larval Scomber scombrus.

On the other hand the metabolic coefficients in Equations (4) and (5) differ significantly among the 2 estimation methods (F-test, $p<0.01$ ). Although the difference is small, this suggests that our estimate using the linear regression method is somewhat biased in spite of our precautions (see 'Statistical methods').

We also computed the Q10, an index which indicates the effect of a $10 \mathrm{C}^{\circ}$ increase on metabolic rates (Pros- 


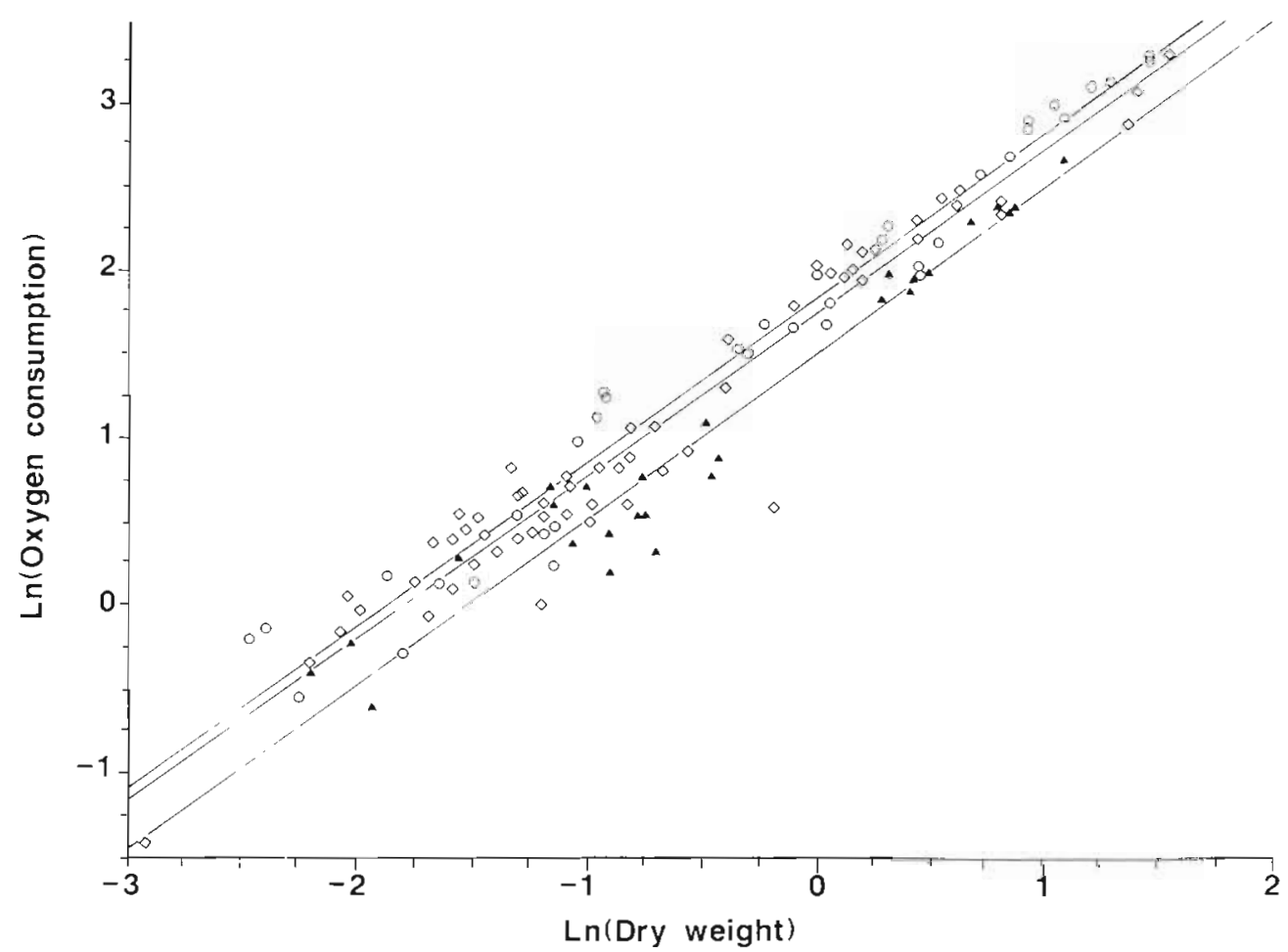

Fig. 1. Scomber scombrus. Rate of oxygen consumption or routine metabolic rate (RMR) of larval Atlantic mackerel as a function of dry body weight (mg). Rate of oxygen consumption is given as $\mu \mathrm{h} \mathrm{h}^{-1}$ ind. ${ }^{-1}$. Top, middle and bottom lines: best least squares fits at 13 (triangles), 16 (lozenges) and $19^{\circ} \mathrm{C}$ (circles) respectively

ser 1973, Ikeda 1985). According to Equations (4) and (5), RMR increased by a factor of 1.7 and 1.6 for a $10 \mathrm{C}^{\circ}$ increase in temperature respectively (e.g. $Q 10=$ $e^{0.05810}=1.7$ ). This result is in line with values obtained for standard metabolic rates of fish in general (Peters 1983).

Finally, we compared RMR of fed (see equation below) and unfed larvae (Equation 2) at $16^{\circ} \mathrm{C}$. We note that feeding has (1) no significant effect on the metabolic exponent (analysis of covariance, $p>0.25$ ), (2) a significant effect on the metabolic coefficients ( $p<$ $0.01)$. We conclude from this result that fed larvae consume oxygen at 2.68 times the rate of unfed larvae. The relationship between $\operatorname{RMR}\left(\mu \mathrm{h} \mathrm{h}^{-1}\right.$ ind. $\left.{ }^{-1}\right)$ and $\mathrm{W}$ for fed larvae is:

$$
16^{\circ} \mathrm{C} \quad \mathrm{RMR}=4.608 \mathrm{~W}^{1.01} \mathrm{r}^{2}=0.95 \quad n=8
$$

\section{DISCUSSION}

\section{Do routine metabolic rates scale isometrically in larval fishes?}

We determined routine metabolic rates (RMR) in larval Scomber scombrus, paying particular attention to the scaling of metabolic rates with respect to body weight (W). The power function of the relationship between RMR and $W$ scale as $W^{1.00}$, i.e. the scaling is isometric since the exponent is 1 . Hence metabolic rates vary in direct proportion to the body weight of larvae. Results published for other species range from 0.65 to 1.69 (Table 1). The mean of those tabled is 0.97 (Standard error $=0.039$, sample size $=29$ ). Because the distribution of values is skewed, the geometric mean represents a better measure of central tendency. It is 0.95 . These values could be erroneous however, because methodological biases are common and confounded among experiments. We tried to sort out potential biases by regressing the metabolic exponents given in Table 1 on the following: volume of respiration chamber, temperature, sample size, maximum number of fish in a chamber, maximum density of fish in a chamber, weight of smallest larva, and weight of largest larva. Also included in the regression were dummy variables to take into consideration differences in techniques: measurement method $10=$ manometric, 1 = polarographic oxygen electrode or Winkler) and preservation method $(0=$ none, $1=$ formaldehyde or freezing). None of these factors were statistically significant ( $p \geq 0.25$ ) except preservation method ( $p \leq 0.05$ ). The results indicate that chemical preservation of specimens prior to dry weight determination lowers the metabolic exponent by about 0.14 . 
Table 1. Summary of methods and statistics for various studies on the metabolism of larval marine fishes. Metabolic exponents estimated using a predictive equation have been corrected according to a functional equation (Ricker 1973): b: = metabolic exponent; $\mathrm{r}^{2}=$ coefficient of determination (sample size); Ind $=$ no. of fish in chamber; Vol = Median value for volume of chamber; $T=$ temperature; $W o=$ dry wt of smallest larva or group of larvae; $W f=$ dry wt of largest larva or group of larvae

\begin{tabular}{|c|c|c|c|c|c|c|c|c|}
\hline $\mathrm{b}$ & $r^{2}$ & Ind & $\begin{array}{l}\text { Vol } \\
(\mathrm{ml})\end{array}$ & $\begin{array}{c}\mathrm{T} \\
\left({ }^{\circ} \mathrm{C}\right)\end{array}$ & $\begin{array}{l}\text { Wo } \\
(\mathrm{mg})\end{array}$ & $\begin{array}{c}\text { Wf } \\
(\mathrm{mg})\end{array}$ & Species & Source \\
\hline 0.65 & $0.71(20)$ & $1-10$ & 10 & 9 & 0.05 & 1.86 & M. aeglefinus & Laurence (1978) \\
\hline 0.67 & $0.95(253)$ & $?-10$ & 5 & 10 & 0.05 & 10.00 & P. platessa & De Silva \& Tytler (1973) \\
\hline 0.70 & $0.70(17)$ & 1 & 110 & 16 & 0.14 & 2.70 & E. mordax & Theilacker (1987) \\
\hline 0.74 & $0.98(6)$ & $4-10$ & 5 & 8 & 0.15 & 0.50 & C. harengus ${ }^{a}$ & Almatar (1984) \\
\hline 0.74 & $0.99(6)$ & $4-10$ & 5 & 18 & 0.10 & 0.75 & P. platessa ${ }^{a}$ & Almatar (1984) \\
\hline 0.80 & $0.95(5)$ & $4-10$ & 5 & 8 & 0.08 & 0.80 & P. plates $5 a^{\mathrm{a}}$ & Almatar (1984) \\
\hline 0.83 & $0.73(72)$ & $10-50$ & 40 & 16 & 0.02 & 0.14 & E. mordax & Theilacker (1987) \\
\hline 0.87 & $0.92(9)$ & $1-35$ & 6 & 26 & 0.02 & 0.07 & A. rhomboidalis ${ }^{\mathrm{C}}$ & Houde \& Schekter (1983) \\
\hline 0.88 & $0.83(24)$ & $4-21$ & 300 & $16^{\bullet}$ & 0.31 & 27.20 & P. olivaceus $s^{a, c}$ & Morioka (1985) \\
\hline 0.91 & $0.87(6)$ & $4-10$ & 5 & 18 & 0.10 & 0.65 & C. harengus ${ }^{\mathrm{a}}$ & Almatar (1984) \\
\hline 0.92 & $0.55(26)$ & $1-10$ & 10 & 7 & 0.05 & 0.48 & $M$. aeglefinus & Laurence (1978) \\
\hline 0.92 & $0.56(47)$ & $1-10$ & 10 & 10 & 0.06 & 2.01 & G. morhua & Laurence (1978) \\
\hline 0.96 & $0.59(20)$ & $1-10$ & 10 & 8 & 0.01 & 1.00 & P. americanus & Laurence (1975) \\
\hline 0.97 & $0.94(28)$ & 1 & 40 & 13 & 0.11 & 2.92 & S. scombrus ${ }^{\mathrm{c}}$ & This study \\
\hline 0.97 & $0.64(37)$ & $1-10$ & 10 & 7 & 0.05 & 1.22 & G. morhua & Laurence (1978) \\
\hline 0.98 & $0.98(6)$ & $4-10$ & 5 & 8 & 0.08 & 1.20 & P. platessa ${ }^{a}$ & Almatar (1984) \\
\hline 0.99 & $0.98(37)$ & 1 & 40 & 19 & 0.08 & 4.23 & S. scombrus ${ }^{c}$ & This study \\
\hline 1.00 & $0.95(58)$ & 1 & 40 & 16 & 0.05 & 4.56 & S. scombrus ${ }^{\mathrm{c}}$ & This study \\
\hline 1.00 & $0.96(11)$ & $1-35$ & 6 & 26 & 0.01 & 0.42 & A. mitchillic ${ }^{\mathrm{c}}$ & Houde \& Schekter (1983) \\
\hline 1.05 & $0.96(11)$ & $?-7$ & 10 & 24 & 0.03 & 0.60 & S. aurata ${ }^{\mathrm{c}}$ & Quantz \& Tandler (1984) \\
\hline 1.05 & $0.62(16)$ & $1-10$ & 10 & 5 & 0.01 & 1.00 & P. americanus & Laurence (1975) \\
\hline 1.07 & $0.59(110)$ & $\xi-10$ & 5 & 10 & 0.10 & 10.00 & C. harengus ${ }^{a}$ & De Silva \& Tytler (1973) \\
\hline 1.08 & $0.84(33)$ & $?-7$ & 10 & 19 & 0.03 & 1.00 & S. auratac & Quantz \& Tandler (1984) \\
\hline 1.10 & $1.00(2)$ & $1-10$ & 10 & 9 & 0.04 & 0.10 & C. harengus & Holliday et al. (1964) \\
\hline 1.10 & $0.73(14)$ & $1-35$ & 6 & 28 & 0.01 & 0.25 & A. lineatus ${ }^{\mathrm{C}}$ & Houde \& Schekter (1983) \\
\hline 1.10 & $0.66(48)$ & $5-20$ & 10 & 7 & 0.01 & 0.10 & $P$. americanus $^{\mathrm{d}}$ & Cetta \& Capuzzo (1982) \\
\hline 1.13 & $0.56(17)$ & $1-10$ & 10 & 2 & 0.01 & 1.00 & P. americanus & Laurence (1975) \\
\hline 1.34 & $0.98(6)$ & $4-10$ & 5 & 13 & 0.12 & 0.60 & C. harengus ${ }^{a}$ & Almatar (1984) \\
\hline 1.69 & $0.56(19)$ & $1-10$ & 10 & 4 & 0.07 & 0.21 & M. aeglefinus & Laurence (1978) \\
\hline
\end{tabular}

This result is in agreement with Hay's (1984) findings for larval herring of similar size. We corrected the metabolic exponents in Table 1 by adding 0.14 in all cases where larvae were preserved prior to dry weight determination. This yielded a revised mean metabolic exponent of 1.02 (Standard error $=0.038$, sample size $=29$ ) for all studies cited in Table 1; the geometric mean is 1.00 Data from fresh water species are scanty, but in a well-studied representative, the carp Cyprinus carpio, isometric relationships between metabolic rates and weight have been reported. The metabolic exponent of the power function relating body weight and RMR in the larval stage is 0.95 according to Winberg \& Khartova (1953), and 0.97 according to Kamler (1976). Values ranging from 0.76 to 0.85 have been reported for juveniles weighing more than $1 \mathrm{~g}$ (Winberg 1956, Kaush 1968, Melnichuk 1969, Kamler 1976).

\section{Do standard metabolic rates scale isometrically in larval fishes?}

Whereas routine metabolic rates scale isometrically with respect to body weight in larval fishes, standard metabolic rates (SMR) could scale differently if the metabolic exponent is affected by spontaneous activity. Brett (1964) estimated metabolic exponents for juvenile sockeye salmon Oncorhynchus nerka exhibiting 0, 25, 50,75 and $100 \%$ of maximum activity. They were 0.78 , $0.85,0.88,0.92$, and 0.97 respectively. Since it is held that the metabolic rate of a fully active individual is about 10 times SMR (Brett 1964, Peters 1983, SchmidtNielsen 1984), and that of individuals exhibiting routine levels of activity is only about 2 or 3 times SMR (Ware 1975), routine activity is not likely to raise metabolic exponents significantly. In other words, we expect SMR and RMR to scale in similar fashion. 


\section{Implications}

In larval fishes, routine metabolic rates scale isometrically, that is they increase in direct proportion to body weight $\left(\mathrm{W}^{1.00}\right)$ whereas in juveniles and adult fish, they scale according to the $W^{0.8}$ allometric law (Peters 1983). This suggests that, as one organism passes from one life-history stage to the next, the metabolic exponent decreases as the overall body size of the organism increases. Such a relationship has been observed interspecifically (Zeuthen 1953) and intra-specifically (in marine cephalopods, Johansen et al. 1982).

Since metabolic rates and body size vary isometrically in larval fish, this implies that to meet metabolic costs, an animal twice the size of another one must ingest twice as much food. Conversely, when larvae are starved, weight losses will be directly proportional to body weight. Using the $W^{0.8}$ law to study the energetics of fish larvae would clearly result in metabolic costs being inadequately assessed.

Acknowledgements. We thank the staff and C. LeBreton of the Centre Marin, Shippagan, New Brunswick. J. R. Brett, R. L. Dunbrack, H. J. Fyhn and W. Nagata kindly reviewed the manuscript. J. Hunter. C. Kimbrell, J. Marliave and P. Pearly provided advice on culturing larval fishes. Contribution of 'Centre de Recherche en Ecologie des Pêches

\section{LITERATURE CITED}

Almatar, S. M. (1984). Effects of acute changes in temperature and salinity on the oxygen uptake of larvae of herring (Clupea harengus) and plaice (Pleuronectes platessa). Mar Biol. 80: 117-124

Brett, J. R. (1964). The relation of size to rate of oxygen consumption and sustained swimming speed of sockeye salmon (Onchorhynchus nerka). J. Fish. Res. Bd Can. 22 1491-1501

Carritt, D. E., Carpenter, J. H. (1966). Comparison and evaluation of currently employed modifications of the Winkler method for determining dissolved oxygen in seawater. J. mar. Res. 24: 286-318

Cetta, C. M., Capuzzo, J. M. (1982). Physiological and biochemical aspects of embryonic and larval development of the winter flounder Pseudopleuronectes americanus. Mar. Biol. 71. 327-337

De Silva, C. D., Tytler, P. (1973). The influence of reduced environmental oxygen on the metabolism and survival of herring and plaice larvae. Neth. J. Sea Res. 7: 345-362

Donhoffer, Sz. (1986). Body size and metabolic rate: exponent and coefficient of the allometric equation. The role of units. J. theor. Biol. 119: 125-137

Fry, F. E. J. (1957). The aquatic respiration of fish. In: Brown, M. E. (ed.) The physiology of fishes, Vol. I. Academic Press, New York, p. 1-63

Giguère, L. A., Bernier, B., St-Pierre, J.-F., Vézina, A., Rondeau, J.-G. (in press). Can we estimate the true weight of zooplankton samples after chemical preservation? Can. J. Fish. Aquat. Sci.
Glass, N. R. (1969). Discussion of calculation of power function with special reference to respiratory metabolism in fish. J. Fish. Res. Bd Can. 26: 2643-2650

Gould, S. J. (1966). Allometry and size in ontogeny and phylogeny. Biol. Rev. 41.587-640

Hay, D. E. (1984). Weight loss and change of condition factor during fixation of Pacific herring, Clupea harengus pallasi, eggs and larvae. J. Fish Biol. 25: 421-433

Hedley-Whyte, J., Radford, E. P., Laver, M. W. (1965). Nomogram for temperature correction or electrode calibration during $\mathrm{pO}_{2}$ measurements. J. Appl. Physiol. 20: 785-786

Holliday, F. G. T., Blaxter, J. H. S., Lasker, R. (1964). Oxygen uptake of developing eggs and larvae of the herring (Clupea harengus). J. mar. biol. Ass. U.K. 44: 711-723

Houde, E. D., Schekter, R. C. (1983). Oxygen uptake and comparative energetics among eggs and larvae of three subtropical marine fishes. Mar. Biol. 72: 283-293

Hughes, J. T., Schleser, R. A., Tchobanoglous, G. (1974). A rearing tank for lobster larvae and other aquatic species. Progve Fish Cult. 36: 129-132

Hunter, J. H., Kimbrell, C. A. (1980). Early life history of pacific mackerel, Scomber japonicus. Fish. Bull. U.S. 78: 89-101

Ikeda, T. (1985). Metabolic rates of epipelagic marine zooplankton as a function of body mass and temperature. Mar. Biol. 85: 1-11

Johansen, K., Brix, O., Kornerup, S., Lykkeboe, G. (1982). Factors affecting O2-uptake in the cuttlefish, Sepia officinalis. J. mar. biol. Ass. U.K. 62: 187-191

Kamler, E. (1976). Variability of respiration and body composition during early developmental stages of carp. Pol. Arch. Hydrobiol. 23: 431-485

Kaush, H. (1968). Der Einfluß der Spontanaktivität auf die Stoffwechselrate junger Karpfen (Cyprinus carpio L.) im Hunger und bei Fütterung. Arch. Hydrobiol. 33 (Suppl.): 263-330

Kleiber, M. (1961). The fire of life. An introduction to animal energetics. Wiley, New York

Laughlin, R. B., Wofford, H. W., Neff, J. M. (1979). Simple potientometric method for the rapid determination of respiration rates of small aquatic organisms. Aquaculture 16: $77-82$

Laurence, G. C. (1973). Influence of temperature on energy utilization of embryonic and prolarval tautog, Tautoga onitis. J. Fish. Res. Bd Can. 30: 435-442

Laurence, G. C. (1975). Laboratory growth and metabolism of the winter flounder Pseudopleuronectes americanus from hatching through metamorphosis at three temperatures. Mar Biol. 32: 223-229

Laurence, G. C. (1978). Comparative growth, respiration and delayed feeding abilities of larval cod (Gadus morhua) and haddock (Melanogrammus aeglefinus) as influenced by temperature during laboratory studies. Mar. Biol. 50: 1-7

Laws, E. A., Archie, J. W. (1981). Appropriate use of regression analysis in marine biology. Mar. Biol. 65: 13-16

Lubzens, E. (1987). Raising rotifer for use in aquaculture. Hydrobiol. 147. 245-255

Melnichuk, G. L. (1969). Metabolism intensity in fry of foodfish from the Kremenchug reservoir. Gidrobiol. Zh. Kiv 5: $66-71$

Morioka, Y (1985). Growth, respiration and food requirement of a flounder, Paralichthys olivaceus, in its early life history. Bull. Seikai Reg. Fish. Res. Lab. 62: 67-77

Mittertreiner, A., Schnute, J. (1985). Simplex: a manual and software package for easy non-linear parameter estimation and interpretation in fishery research. Can. Tech. Rep. Fish. Aquat. Sci. No. 1384: 1-90 
Peters, R. H. (1983). The ecological implications of body size. Cambridge University Press, Cambridge

Prosser, C. L. (1973). Comparative animal physiology. Saunders, Philadelphia

Quantz, G., Tandler, A. (1984). The effect of weight and environmental temperature on the oxygen consumption of gilthead seabream (Sparus aurata L.) larvae. In: Rosenthal, H., Sarig, S. (eds.) Research on aquaculture. European Mariculture Society, Spec. Publ. No. 8, Bredene, Belgium, p. $229-239$

Reguera, B. (1984). The effect of ciliate contamination in mass cultures of the rotifer $B$. plicatilis O. F. Müller. Aquaculture 40: $103-108$

Ricker, W. E. (1973). Linear regressions in fishery research. Linear function with special reference to respiratory metabolism in fish. J. Fish. Res. Bd Can. 30: 409-434
Schmidt-Nielsen, K. (1984). Scaling. Why is animal size so important? Cambridge University Press, Cambridge

Theilacker, G. H. (1987). Feeding ecology and growth energetics of larval northern anchovy, Engraulis mordax. Fish Bull. U.S. 85: 213-228

Ware, D. M. (1975). Bioenergetics of pelagic fish: theoretical change in swimming speed and ration with weight. J. Fish Res. Bd Can. 35: 220-228

Winberg, G. G. (1956). Rate of metabolism and food requirement of fishes (Russian). Nauch. Tr. Beloruss. Gos. Univ. Minsk. Translated (1960): Fish. Res. Bd Can. Trans. Ser 194: 1-202

Winberg, G. G., Khartova, L. E. (1953). Rate of metabolism in carp fry. Dokl. Akad. Nauk SSSR 89: 1119-1122

Zeuthen, E. (1953). Oxygen uptake as related to body size in organisms. Q. Rev. Biol. 28: 1-12

This article was presented by Dr D. Alderdice; it was accepted for printing on August 3, 1988 